\title{
Premio al Esfuerzo: Mejores Trabajos de Investigación 2009
}

\author{
PAUL R. HARRIS ${ }^{1}$ \\ 1. Miembro Comité Editorial Revista Chilena de Pediatría. Coordinador Comisión Investigación, \\ Sociedad Chilena de Pediatría.
}

La investigación científica original por definición constituye una de las más importantes metas de las sociedades científicas. Todos los conocimientos que aplicamos en nuestra práctica diaria en relación a diagnóstico y tratamiento de nuestros pacientes, provienen de la esforzada y generosa labor de investigación de nuestros pares a lo largo de los tiempos. La Revistas biomédicas se han transformado en el principal medio de difusión de los resultados de dicha investigación, siendo la publicación la etapa final de un largo proceso de investigación por parte de los autores o investigadores. El gran valor de esta herramienta es que representa un proceso arbitrado por pares, expertos en el tema, lo cual asegura que la experiencia presentada es efectivamente una contribución al conocimiento médico. A su vez, cada trabajo o manuscrito publicado es la piedra inicial para iniciar un nuevo trabajo, al generar nuevos conocimientos, inquietudes y motivaciones entre los pares lectores.

Cuando una Revista científica es al mismo tiempo el órgano oficial de una Sociedad científica, la tarea de difundir la labor científica se torna un imperativo. Es por esto que la Sociedad Chilena de Pediatría (SOCHIPE) cumpliendo sus objetivos fundacionales, ha generado instancias para financiar proyectos de investigación, ha abierto espacios para concursos de mejores trabajos presentados en los congresos anuales de la misma sociedad y ha permitido la generación de reconocimiento público a aquellos investigadores que han destacado con sus trabajos científicos.

La Comisión de Investigación (CI) de la Sociedad Chilena de Pediatria se hace un deber felicitar y destacar el arduo, consistente, y comprometido trabajo de los pediatras y residentes (becados) de pediatría en su afán de diseñar, ejecutar, evaluar y presentar los resultados de su investigación, frente las respectivas comisiones de pares, partiendo por los asistentes a los congresos y lectores de sus trabajo.

El Congreso de Pediatría 2009 en Valdivia, permitió evaluar a más de 350 trabajos en formato resumen ("abstracts"), de los cuales sobre 250 fueron seleccionados para presentación en formato poster o plataforma (presentación "oral"). Las respectivas Ramas y Comités de SOCHIPE preseleccionaron un total de 20 trabajos de acuerdo a criterios propios y a los criterios sugeridos por la Comisión de Investigación. Luego, la CI seleccionó aquelos que cumplían estándares preestablecidos, 11 en este caso, a los cuales se les solicitó presentar el trabajo en formato manuscrito para ser expuestos en presentación oral durante el XLIX Congreso Chileno de Pediatría, los días 29 y 30 de Octubre. Los evaluadores (Directorio de SOCHIPE y los miembros de la CI) asignaron un puntaje (de 1 a 5) a 7 variables (tabla 1),

Correspondencia a:

Dr. Paul R Harris

E-mail:pharris@med.puc.cl 
Tabla 1. Elección de Trabajos para premios por la CI

\begin{tabular}{ccccccccc}
\hline $\begin{array}{c}N^{\circ} \text { asignado } \\
\text { al trabajo }\end{array}$ & $\begin{array}{c}\text { Nombre y } \\
\text { Apellido, } \\
\text { Autor } \\
\text { principal }\end{array}$ & $\begin{array}{c}\text { Categoría: } \\
\text { Becado (B), } \\
\text { General (G) }\end{array}$ & $\begin{array}{c}\text { Calidad de } \\
\text { la presen- } \\
\text { tación oral }\end{array}$ & $\begin{array}{c}\text { Claridad de } \\
\text { objetivo e } \\
\text { hipótesis }\end{array}$ & $\begin{array}{c}\text { Metodología } \\
\text { adecuada }\end{array}$ & $\begin{array}{c}\text { Resultados Conclusiones } \\
\text { claros Calidad } \\
\text { consistentes }\end{array}$ & $\begin{array}{c}\text { Habilidad los } \\
\text { deara } \\
\text { diapositivos }\end{array}$ & $\begin{array}{c}\text { Score } \\
\text { responder } \\
\text { preguntas }\end{array}$ \\
\hline
\end{tabular}

Tabla 2. Premios a los mejores trabajos presentados en el XLIX Congreso Chileno de Pediatría, Año 2009

\begin{tabular}{|c|c|c|c|c|}
\hline Categoría & & Trabajo & Autores & Afiliación \\
\hline \multirow[t]{3}{*}{ General } & $1^{\circ}$ lugar & $\begin{array}{l}\text { Screening de Desarrollo Psicomotor } \\
\text { en la Consulta Pediátrica: Evaluación } \\
\text { del una prueba de auto-reporte de } \\
\text { los padres }\end{array}$ & $\begin{array}{l}\text { L Schonhaut, P Salinas, } \\
\text { I Armijo, M Schonsteadt, } \\
\text { J Alvarez, M Manriquez }\end{array}$ & $\begin{array}{l}\text { Facultad de Medicina } \\
\text { Clínica Alemana-Universidad } \\
\text { del Desarrollo }\end{array}$ \\
\hline & $2^{\circ}$ lugar & $\begin{array}{l}\text { Estudio de la asociación entre el uso } \\
\text { de antibióticos y la expresión de } \\
\text { betalactamasas de espectro extendido } \\
\text { (BLEEE) en agentes asilados de epi- } \\
\text { sodios bacteremicos, } 4 \text { años de } \\
\text { experiencia }\end{array}$ & $\begin{array}{l}\text { M Acuña, D Benadof, } \\
\text { P Rodriguez, A Ginesta, } \\
\text { P Herrera }\end{array}$ & Hospital Roberto del Río \\
\hline & $3^{\circ}$ lugar & $\begin{array}{l}\text { Prevalencia de IgG anti CMV en } \\
\text { embarazadas al momento del parto }\end{array}$ & $\begin{array}{l}\text { M Yamamoto, P Prado, } \\
\text { J Wilheim, R Bradford, } \\
\text { J Novoa, F Lira, } \\
\text { A Insunza, J Carrillo, } \\
\text { L Vergara, E Paiva }\end{array}$ & $\begin{array}{l}\text { Hospital Padre Hurtado, } \\
\text { Facultad de Medicina } \\
\text { Clínica Alemana-Universidad } \\
\text { del Desarrollo } \\
\text { Depto. de Pediatría. T University } \\
\text { of Alabama at Birmingham. } \\
\text { Escuela de Medicina, Universidad } \\
\text { Católica de Chile }\end{array}$ \\
\hline Becados & $1^{\circ}$ lugar & $\begin{array}{l}\text { Factores asociados a la realización } \\
\text { del test Elisa VIH en embarazadas }\end{array}$ & $\begin{array}{l}\text { C Flores, S Flores, } \\
\text { M Andia, E Donoso, } \\
\text { M Torres, P Bedregal, } \\
\text { G Valdivia }\end{array}$ & $\begin{array}{l}\text { Pontificia Universidad Católica de } \\
\text { Chile. Depto. de Salud Pública, } \\
\text { Programa de Magister de Epide- } \\
\text { miología, Hospital Provincial de } \\
\text { Ovalle, Servicios de Pediatría y } \\
\text { Ginecología-Obstetricia. }\end{array}$ \\
\hline
\end{tabular}

logrando un puntaje mínimo de 7 y máximo de 35. En esta forma se pretende obtener un número de 3 trabajos para premio en categoría general y 3 trabajos en categoría becados. Si la evaluación no alcanza el $80 \%$ del puntaje máximo, puede eventualmente quedar uno ó más premios desiertos, en la búsqueda de estándares que eleven permanentemente el nivel de la investigación pediátrica en nuestra Sociedad. De este modo se seleccionaron este año los 3 mejores trabajos en categoría general y 1 trabajo en categoría becados. Dicha premiación se realizó el Sábado 31 de Octubre en la Ceremonia de Clausura del Congreso con presencia de las autoridades de SOCHIPE y asistentes al
Congreso. En esta Editorial hacemos llegar nuestras más sinceras felicitaciones a los ganadores (tabla 2), concientes de la importancia que tiene el reconocer el esfuerzo de investigar para generar nuevo conocimiento, a pesar de la importantes limitaciones que esta disciplina presenta en nuestra realidad nacional.

Adicionalmente, en dicho Congreso se entregaron los premios correspondientes a los mejores trabajos publicados en la Revista Chilena de Pediatría, selección realizada por el Comité Editorial de la Revista, y que evalúa los últimos 6 números publicados previo al Congreso, correspondientes a un año calendario. De este modo se asignaron los premios a los 3 
Tabla 3. Premios a los mejores trabajos publicados en la Revista Chilena de Pediatría, Año 2008-2009

\begin{tabular}{|c|c|c|c|c|}
\hline Categoría & & Trabajo & Autores & Afiliación \\
\hline \multirow[t]{3}{*}{ General } & 10 lugar & $\begin{array}{l}\text { Lenguaje e inteligencia de preesco- } \\
\text { lares: análisis de su relación y factores } \\
\text { asociados } \\
\text { Rev Chil Pediatr 2008; 79(6): 600-606 }\end{array}$ & $\begin{array}{l}\text { L Schonhaut, M Maggiolo, } \\
\text { ME Herrera, K Acevedo, } \\
\text { M García }\end{array}$ & $\begin{array}{l}\text { Departamento Pediatría y Cirugía } \\
\text { Infantil Campus Norte, Facultad } \\
\text { de Medicina, Universidad de } \\
\text { Chile }\end{array}$ \\
\hline & $2^{\circ}$ lugar & $\begin{array}{l}\text { Autoreporte de la calidad de vida en } \\
\text { niños y adolescentes escolarizados } \\
\text { Rev Chil Pediatr 2009; 80(3): 238-244 }\end{array}$ & $\begin{array}{l}\text { A Urzúa, E Cortés, L Prieto, } \\
\text { S Vega, K Tapia }\end{array}$ & $\begin{array}{l}\text { Escuela de Psicología, Universidad } \\
\text { Católica del Norte. Antofagasta, } \\
\text { Chile }\end{array}$ \\
\hline & $3^{\circ}$ lugar & $\begin{array}{l}\text { Curvas antropometricas de recien } \\
\text { nacidos chileno } \\
\text { Rev Chil Pediatr 2008; 79(4): 364-372 }\end{array}$ & $\begin{array}{l}\text { J Alarcón, Y Alarcón, } \\
\text { E Hering, R Buccioni. }\end{array}$ & $\begin{array}{l}\text { Servicio de Neonatología, } \\
\text { Hospital Santiago Oriente Luis } \\
\text { Tisné Brouse. Servicio de } \\
\text { Neonatología, Hospital del } \\
\text { Salvador }\end{array}$ \\
\hline Becados & & $\begin{array}{l}\text { Sindrome febril sin foco y sospecha } \\
\text { de infección bacteriana en niños } \\
\text { entre } 6 \text { semanas y } 36 \text { meses } \\
\text { Rev Chil Pediatr 2008; 79(4): 388-392. }\end{array}$ & $\begin{array}{l}\text { X IBarra, T Viviani, } \\
\text { A M Peña, J Cerda }\end{array}$ & $\begin{array}{l}\text { Departamento de Pediatría y } \\
\text { Salud Pública, Pontificia } \\
\text { Universidad Católica de Chile. } \\
\text { Unidad de Infectología } \\
\text { Pediátrica, Hospital Dr. Sótero } \\
\text { del Río }\end{array}$ \\
\hline
\end{tabular}

mejores trabajos en categoría general y al mejor trabajo en categoría becados (Premio auspiciado por Nestlé Nutrition). Dicha premiación se realizó el Viernes 30 de Octubre con presen- cia de las autoridades de SOCHIPE y asistentes al Congreso. Nuestras sinceras felicitaciones a los autores de cada uno de los trabajos (tabla 3).

\section{A LOS AUTORES}

Comunicamos a los autores de los artículos presentados para publicación en Revista Chilena de Pediatría, que ha concluido exitosamente el Proyecto Editorial del Fondo de Publicación de Revistas Científicas CONICYT 2008-2009 «Revista Chilena de Pediatría: De las Publicaciones en Papel a un Proceso Editorial On-Line basado en Open Journal System». Por lo tanto, solicitamos a los autores de los artículos presentados a partir de ahora, que ingresen a www.revistachilenadepediatria.cl, se registren e identifiquen de acuerdo a las instrucciones, y procedan a ingresar su contribución al sistema editorial electrónico según se detalla.

La Sociedad Chilena de Pediatria y Revista Chilena de Pediatría se enorgullecen de poner a disposición de nuestros colaboradores esta moderna herramienta editorial, en forma pionera entre las publicaciones biomédicas de nuestro país.

El Editor 